\title{
REVIEW
}

\section{Human's spiritual evolution through a girl's eyes: The unique vision of Kalina Stefanova}

\begin{abstract}
Yue Wang
Abstract: Kalina Stefanova's Ann's Dwarves and The Last Way Out were originally written in Bulgarian and published as two loose sequel-fictions in 2004 and 2010. During the last decade, thirteen distinct translations were done. This review attempts to give readers a brief introduction of the author and her two fictions as well as their reception and criticism. As her review writer, I firmly hold the opinion that Stefanova has been providing samples of cosmopolitan writing about human's communication with the cosmos since ancient times, and human's spiritual evolution - all this through the girl protagonist Ann's eyes. This reveals the author's unique vision and her inner life of tranquility and freedom.
\end{abstract}

Keywords: inner life, Kalina Stefanova, Ann's Dwarves, The Last Way Out

\section{Introduction}

There mysteriously is a dearth of scholarship on children's literature by Kalina Stefanova. Perhaps such absence stems from the complicated position of her two fiction books, which can be regarded as semiautobiographical and are delightful ventures into storytelling with a daring crossing of the genres. In the first place, like all good fairy tales (a modern fairy tale was the initial subtitle of Ann's Dwarves), these books are tales about our inner life. Indeed, Stefanova's view on both life and the cosmos beneath the surface narrative could be of help to almost every reader. No wonder she is compared to Antoine de Saint Exupery: she has a similar ability to express the inexpressible, her narrative being full of subtext.

Ann's Dwarves has been translated and published in nine countries, and has two editions in China. It has been included in the indicative reading lists for literature in some Brazilian colleges. The Last Way Out has been translated and published in three countries so far.

The two books are loosely connected mainly via the chief protagonist Ann and to an extent via the other characters. Ann's Dwarves is deceptively simple at first reading. It is based on the premise that one day Ann sees for

Received: February 24, 2020; Accepted: March 17, 2020; Published: March 19, 2020 Correspondence to: Yue Wang, School of Chinese Language and Literature, Hubei Normal University, Huangshi 435002, China; Email: hbnu_yuewang@qq.com

Citation: Wang Y. Human's spiritual evolution through a girl's eyes: The unique vision of Kalina Stefanova. Int J Arts Humanit, 2020, 1(1): 13-15.

Copyright: (c) 2020 Yue Wang. This is an open access article distributed under the terms of the Creative Commons Attribution License, which permits unrestricted use, distribution, and reproduction in any medium, provided the original author and source are credited. the first time her dwarves who, it turns out, have always been with her. This discovery leads her into rediscovering the whole world around her - a secret, as she is to learn, is already well known to her mom and many other people also able to see their own dwarves.

Albeit a loose sequel to Ann's Dwarves, The Last Way Out can actually be read as a stand-alone too. On a sunny late afternoon in Frankfurt, during the Book Fair, the hardly unusual appearance of a chocolate-brown dog triggers a mysterious chain of events. They unfold against a background of other cities around the world, now and in days of yore, in the air and in a mean city, in reality and in dreams, and end with the successful crossing of a metaphorical rope bridge, thin and unsafe, above a deep chasm. Meanwhile a succession of secrets is being revealed: about the existence of the Spiritual Bank, generators of thoughts and thought-mufflers (junk-thoughts being one of them), about the mission of animals today, about the role of Anti-Nature and about the last magical power of people, and a lot more. On the surface, this unusual book could be taken as a fantasy based on reality. On a deeper level, though, The Last Way Out is a very timely and topical read, since it provides the readers with kind of a 'lens' through which the current state of the world turns out to be in direct correlation with the state of our souls.

Ann's Dwarves editions: (1) Bulgaria, Bulgarian Bestseller, in Bulgarian (2004); in English for the territory of Bulgaria (2004, 2006); (2) Macedonia, Makavej, in Macedonian, 2007; (3) South Korea, Kayanet, in Korean, 2007; (4) Portugal, Vogais, in Portuguese, 2010; (5) Spanish World Rights, Alfaomega, 2010; (6) Brazil, Global 
Editora, June 2011; (7) Japan, Poplar Publishing Co., October 2011; (8) Vietnam, VNN Publishing Agent JSC, 2012; (9) China, The Writers Publishing House, Beijing, Simplified Chinese, September 2012; (10) China, Beijing Bocaiyaji Culture Media Co. second edition, 2018.

The Last Way Out editions: (1) Bulgaria, UNISCORP, 2010; (2) Brazil, Lumen, 2014; (3) China, Beijing Bocaiyaji Culture Media Co, 2019.

\section{Ann's Dwarves, a contemporary Bulgarian fairy tale for all ages}

Ann's Dwarves is a usually defined as a fiction for all ages. Not an ordinary book, it's part game, part philosophy but throughout a story full of goodness. "The most valuable thing in Ann's Dwarves," wrote Mario Nikolov in the Bulgarian Dnevnik, "is that the book delves deep into the spiritual essence of human nature by the means of the fairy tale - that infinite universe dwelled in by the Little Prince and wandered around by Alice. Like them, the main characters here also belong to the world of magic: seven charming dwarves who Ann names after the seven musical notes. 'We, dwarves, are a part of you. We are your inner mirrors - truer than ordinary ones, because by looking at us you are able to see what's inside you, not only what's on the surface,' says one of the miniature characters. Kalina Stefanova's book manages to do exactly that: it gets under the surface of the visible reality in order to reach out to the 'things within us', because it's there where one can find the three most important 'things' everyone is in need of-love, faith and hope (?)."

\section{The reception of Ann's Dwarves}

In 2007 South Korea Ann's Dwarves was the special choice of the Editor-in-chief of Chosun Daily (the biggest Korean daily newspaper), in his section: 'Hot Topic in Culture' (?). The book received an overwhelming rave response in the major sites in Korea, garnering four and five star reader reviews. In the two top sites it elicited more than forty reviews during the first month and a half after the publication of the book. Here are some excerpts: "this story makes me realize very important values. We have to give space to the dwarves in our mind and life. In that way we could find our own purity." "The kind of thinking the book sets us on makes the world warm (?)."

\section{The critics on The Last Way Out}

When The Last Way Out was published in Bulgarian in 2010, the literary critic Georgi Tsankov wrote, "A benevolent sorceress has staked her unequivocal claim to a place in our contemporary literature. Kalina Stefanova is our answer to Antoine de Saint - Exupery and Paulo Coelho. She enchanted us with Ann's Dwarves and, now her new book, The Last Way Out, is a veritable explosion of positive energy. Three generations of women - a daughter, a mother and a grandmother - make their way into the secrets of our being, stand courageously against the forces of destruction and strengthen their ties with Good, Love and Nature. Written elegantly and wisely, mystically and poetically, this masterpiece answers questions which we have for a long while been asking ourselves. In these unspiritual times, any such step towards restoration of the initial harmony is a great artistic feat." Tsvetan Tsvetanov from the National Radio reported that, "While reading The Last Way Out, we not only remember that life's fabric is woven out of miracles but we again start living them out. For it is only a step or two now that divides us from an end of the mankind that is no longer simply a possibility but something quite real - and caused by us at that... The conversation between Muhcho and Ann, the backbone of the narrative, is like a therapy session leading us, with its unconditional goodness, towards that light at the end of the tunnel that each of us secretly hopes to see." And Elena Peneva from Dnes.bg wrote that "The novel is a fantastic and colorful journey towards the inner, spiritual truths... The journey's itinerary follows 'the story of a conversation' in the course of which, via dreams, magic and revelations, three generations of women hand to each other a magical key for the interpretation of reality.... The topics are familiar: the power of consciousness, the direction consumerism leads us to, the harm of anger and fear, and the healing effects of Goodness and Love. The discovery, however, is in the metaphors through which Kalina Stefanova presents all that, and this is what makes The Last Way Out a must read for all fans of the genre."

\section{The Last Way Out and Chinese culture}

Interestingly, in Chapter 8 of The Last Way Out, the narrator uses the third person to describe how the protagonist Ann feels, whereas demonstrating her passion for the Chinese language, the hieroglyphs in particular. Her expression of ecstasy immediately reminded me of the author's infatuation with ancient Chinese philosophy, when I first had a chat with her at Wuhan Tianhe Airport in 2016, a few days before I happened to be the translator of her lectures at the Art School of Wuhan University.

The protagonist Ann believes that drawing the Chinese hieroglyphs is a great joy and, more importantly, that each of them is like a fairy tale (page 97, of the English edition). What a flash of intuition for Stefanova to understand Chinese hieroglyphs in this subtle way! How accurate! Moreover, what follows continues surprising 
us: she illuminates the archaic Chinese characters and the history behind the current written form of several words, illustrating the point with the connotation and sound of the character Yi (intend, intention) as well as the shape of the character Zhi (know, knowledge) and Dao (road) and their combination of today's word Zhidao, with an identical meaning of know-how. She has not only mastered the meaning and the form of those characters, but has also grasped the reason behind the appearance, the essence behind the phenomena, the Chinese logic and the unique pattern of thinking - "the Chinese believed that it was with our hearts that we thought" and "when knowledge is genuine, what we say will be right on the target".

\section{The unique vision of Kalina Stefanova}

This writer is not writing simply fables. Stefanova is writing about human's communication with the cosmos since ancient times, about human's spiritual evolution in history! Such a cosmopolitan take on life she has! What a great girl Ann is, indeed, and what a benevolent writer holds her hand along the road towards her inner self, towards the hidden truths of our life!

It seems that Stefanova rehashes moments from her own childhood and also her later experiences, such as the imaginative memories of the dwarves as her compan- ions and the flight journey with her mom from New York to Puerto Rico and back, and also the Chinese learning experience. Her outspoken and subtle writing style is disarmingly sincere. The tranquil scenery and details all along her (characters') journey which she shares with readers often remind me of her depiction for her hometown with a nostalgic look in her eyes, echoing around in the depths of my soul. Indeed, Stefanova's unique vision towards human's past, present and future is shown subtly intertwined in the context of her own life. Maybe this is where the magic power of Ann comes from.

\section{References}

Nikolov M. Week \& DNEVNIKs weekly supplement for culture, Bulgaria, August 27, 2004.

Kim G. 'Hot Topic in Culture', Man Who Reads Books for You, November 29, 2007.

Stefanova K. Yes 24. Screen Name: This is Alice "Cute Seven Dwarves". Yes 24. Screen Name: Sooning "Meeting a Little Me". Yes 24. Screen Name: Aladdin "The kind of thinking the book sets us on makes the world warm", February 29, 2020. https://cn.yes24.com 